\title{
Human neonatal EEG: Frequency analysis of awake and asleep samples from four areas'
}

\author{
Alexander K. Bartoshuk \\ BROWN UNIVERSITY
}

\begin{abstract}
Abstraet
Asleep samples had more slow (0.8-3.0 cps) and less fast (13-32 cps) activity than low voltage awake samples. Abundance of intermediate frequencies (1.4-6.0 cps) was higher in frontal-precentral than parietal-occipital EEGs; this is consistent with greater neural maturation of precentral gyrus (Conel, 1939). Present results suggest possible quantitative indices of activation level and neural maturation for behavioral studies.
\end{abstract}

\section{Problem}

Quantitative studies of the energy spectrum in human neonatal EEGs are few; apparently none have employed electronic frequency analysis together with statistical evaluation to study changes in the energy spectrum as a function of electrode location and sleep-wakefulness. Such data may aid relating EEGs to differential maturation of underlying neural structures, and provide quantitative indices of cortical maturation and general excitatory state for behavioral studies.

Per cent times of various frequencies have been estimated from intervals between baseline crossings (Bartoshuk \& Tennant, 1964). Results showed reliably more slow activity $(0.3-2.0 \mathrm{cps})$ in asleep than awake samples, and higher percentages of intermediate frequencies (1.4-8.3 cps) in frontal-precentral (FPc) than parietal-occipital (PO) tracings.

In this study, the more rigorous method of electronic frequency analysis (Walter, 1963) was used to investigate differences between awake and asleep samples, and between FPc and PO tracings.

\section{Method}

Ss were 17 full-term human newborns at the Providence Lying In Hospital. Median age was $85 \mathrm{hr}$.

Electrode placements were identical with those described earlier (Bartoshuk \& Tennant, 1964). Bipolar tracings were recorded on a Grass Model 6 EEG at a sensitivity of 50 microvolts per $\mathrm{cm}$ and a time constant of 0.12 ; the high frequency response was down $20 \%$ at 70 cps. These EEGs were recorded on FM tape with an Ampex SP-300 at a tape speed of 3.75 ips. Continuous recordings were also taken of the EKG and stabilimeter activity. Fifty-second samples for frequency analysis were selected from artifact-free segments of the EEG at times when no movements could be observed on the stabilimeter record. A special anterior lead provided a tracing which permitted exclusion of eye movements and blinks. Criteria for selecting awake and asleep samples were those used in the earlier study (Bartoshuk \& Tennant, 1964) which provides illustrative primary tracings from $12 \mathrm{Ss}$. The $17 \mathrm{Ss}$ had acceptable samples of sleep but only 14 had acceptable samples of wakeful- ness. Each sample included 4 simultaneous bipolar tracings. All tape-recorded samples were played back serially through the same filters, of the type described by Meister et al. (1959). The filter output, after halfwave rectification, was amplified and led to a Grass electronic integrator. A Hewlett-Packard (hp) digital voltmeter monitored the integrated voltage and the digital data were printed 4 times a sec.

The system was calibrated by sine wave signals from an $\mathrm{hp}$ low frequency function generator led to the EEG electrode input box, amplified with the time constant and filter settings used to record EEGs, and tape recorded at 3.75 ips. The 11 frequency bands described in Table 1 were obtained with 3 filters and 4 playback speeds. A Hunter timer automatically terminated the integration after a standard period.

All levels of confidence are based on two-tailed tests with the Wilcoxon matched-pairs signed-ranks test.

\section{Results}

Bilateral comparisons revealed similar energy spectra in homologous areas (median correlation was .55). Therefore values from homologous areas were averaged for analyses shown in Table 1 . It may be noted that approximately $75 \%$ of the energy is in frequencies below $8 \mathrm{cps}$, even in low voltage awake samples similar to those shown in Bartoshuk \& Tennant (1964).

Comparisons of awake and asleep samples show reliably more slow activity (below $3 \mathrm{cps}$ ) and less fast activity (above $13 \mathrm{cps}$ ) in asleep samples for either FPC or PO. Intermediate frequencies of 3-12 cps show no significant differences between awake and asleep FPc samples. For PO, however, results are less clear but suggest that at least any activity above $8 \mathrm{cps}$ was present to a greater extent during wakefulness than sleep.

In comparisons of FPc and $\mathrm{PO}$, awake and asleep samples agree in showing reliably higher percentages of 1.4-6.0 cps activity in FPc than PO, and more 16-24 cps activity in PO than PFc.

Additional confirmation that awake and asleep samples differed on the activation dimension is provided by a higher $(p<.02)$ median heart rate in awake $(114.5$ beats/min.) than in asleep samples ( 108.5 beats/min.). Overall EEG amplitude was higher during sleep when total integrated activity was about $170 \%$ that of awake samples $(p<.01)$.

\section{Diseussion}

This study, and our earlier one with different Ss, apparatus, and method of analysis, both show reliably higher percentages of activity below 2 cps during sleep than wakefulness, and reliably more $1.4-6.0 \mathrm{cps}$ activity in FPc than PO tracings. Activity in the $2.8-4.8 \mathrm{cps}$ 
band is noteworthy as a possible indicant of neural maturation because it did not vary significantly with sleep-wakefulness over the range studied, but it was reliably greater in FPc, the area of greater neural maturation (Conel, 1939). One apparent discrepancy between our two studies is that whereas baseline crossing data (Bartoshuk \& Tennant, 1964) showed higher per cent times of 0.3-1.1 cps activity in PO than FPc (both in awake and asleep samples), present results show reliably more $0.8-1.2 \mathrm{cps}$ activity in PO than FPc only in the asleep sample. This failure to confirm the earlier finding for awake samples may be due to the inclusion of too much activity above $1.1 \mathrm{cps}$ in our present filter. We will check this possibiltiy with a new filter designed to have a sharper cutoff above $4.4 \mathrm{cps}$, which will provide the required cutoff at $1.1 \mathrm{cps}$ for EEGs played back at 4 times their recording speed.

Present results also revealed consistent differences in faster activity which could not have been examined satisfactorily in our earlier study with the baseline crossing method. The finding of higher percentages of 13-32 cps activity in awake than asleep is strengthened by the similarity of results for FPc and PO. Additional research will help to delimit more exactly the specific frequencies involved in all the differences observed in Table 1.

In summary, present results demonstrate that the energy spectra of human neonatal EEGs vary systematically with recording area and sleep-wakefulness. These findings have implications for theory and research which still have to be adequately investigated. First, human neonates show cyclic variations in sleep-wakefulness (Dittrichova, 1962) which may be important for stimulation studies. In adults, electromyographic reactions (Bartoshuk, 1959) and cortical evoked responses (Whipple, 1964) vary as a function of sleep-wakefulness. In newborns, cardiac responses were related to sould intensity in accordance with the power law when Ss had awake EEGs (Bartoshuk, 1964), but it is not known how this relation would be alterrd during sleep. Frequency analysis may provide quantitative indices of activation level which would permit quantitative research on the functional relation between response magnitude and activation level. Secondly, do EEG measures of differences between FPc and PO tracings, as hypothesized indices of cortical maturation, correlate with longitudinal EEG data, and with other maturational indices? Lastly, normative data on the energy spectrum of human neonatal EEGs may aid early detection of some brain injuries. This possibility is illustrated by the finding that a characteristic fast rhythm (18-35 cps) occurred in reliably more unmedicated cerebral palsied children before $3 \mathrm{yr}$. of age than later, and in some cases it remained localized over 1-2 yr. intervals (Bartoshuk \& Lindsley, 1960).

\section{References}

BARTOSHUK, A. K. Electromyographic reactions to strong auditory stimulation as a function of alpha amplitude. J. comp. physiol. Psychol., 1959, 52, 540-545.

BARTOSHUK, A. K. Human neonatal cardiac responses to sound: a power function. Psychon. Sci., 1964, 1, 151-152.

BARTOSHUK, A. K., \& LINDSLEY, D. B. An abnormal high voltage fast EEG rhythm in cerebral palsy. Paper read at Eastern Psychol. Ass., New York, 1960.

BARTOSHUK, A. K., \& TENNANT, J. M. Human neonatal EEG correlates of sleep-wakefulness and neural maturation. J. psychiat. Res., 1964, 2, 73-83.

CONEL, J. L. The postnatal development of the human cerebral cortex. 1. The cortex of the newborn. Cambridge: Harvard Univer. Press, 1939.

DITTRICHOVA, J. Nature of sleep in young infants. J. appl. Physiol., 1962, 17, 543-546.

MEISTER, M., SCHWAB, R. S., PETERSEN, E., \& GRASS, A. Simultaneous two channel frequency analyzer with non-electronic (passive) filters. EEG clin. Neurophysiol., 1959, 11, 594-600.

WALTER, W. G. Technique-Interpretation. In D. Hill \& G. Parr (Ed.), Electroencephalography, a symposium on its various aspects. New York: MacMillan, 1963.

WHIPPLE, H. E. (Ed.). Sensory evoked response in man. Ann. N. Y. Acad. Sci., 1964, 112, 1-546.

\section{Note}

1. This research was supported by USPHS Grant NB-04001 and by Research Career Development Award K3-MH-21,837. I thank Robert Grass for advice on the electronic frequency analysis, J. M. Tennant and E. Doherty for assistance with data collection and reduction, and the staffs of Providence Lying In Hospital and Roger Williams General Hospital for their cooperation. 